\title{
Retrospective analysis of salvage surgery for local progression of brain metastasis previously treated with stereotactic irradiation: diagnostic benefit, functional outcome, and prognostic factors
}

Koichi Mitsuya ( $\nabla$ k.mitsuya@scchr.jp)

Shizuoka Cancer Center https://orcid.org/0000-0001-8956-5427

Yoko Nakasu

Shizuoka Kenritsu Shizuoka Gan Center

Nakamasa Hayashi

Shizuoka Kenritsu Shizuoka Gan Center

Shoichi Deduchi

Shizuoka Kenritsu Shizuoka Gan Center

Takuma Oishi

Shizuoka Kenritsu Shizuoka Gan Center

Takashi Sugino

Shizuoka Kenritsu Shizuoka Gan Center

Kazuaki Yasui

Shizuoka Kenritsu Shizuoka Gan Center

Hirofumi Ogawa

Shizuoka Kenritsu Shizuoka Gan Center

Tsuyoshi Onoe

Shizuoka Kenritsu Shizuoka Gan Center

Hirofumi Asakura

Shizuoka Kenritsu Shizuoka Gan Center

Hideyuki Harada

Shizuoka Kenritsu Shizuoka Gan Center

Research article

Keywords: Brain metastasis, Prognostic factor, Radiation necrosis, Recurrence, Stereotactic irradiation, Surgery

Posted Date: December 30th, 2019

DOI: https://doi.org/10.21203/rs.2.19748/v1

License: @ (1) This work is licensed under a Creative Commons Attribution 4.0 International License. Read Full License

Version of Record: A version of this preprint was published at BMC Cancer on April 17th, 2020. See the published version at https://doi.org/10.1186/s12885020-06800-w. 


\section{Abstract}

\section{Background}

Stereotactic irradiation (STI) is a primary treatment for patients with newly diagnosed brain metastases. Some of these patients experience local progression, which is difficult to differentiate from radiation necrosis, and difficult to treat. So far, just a few studies have clarified the prognosis and effectiveness of salvage surgery after STI. We evaluated the diagnostic value and improvement of functional outcomes after salvage surgery. Based on these results, we reconsidered surgical indication for patients with local progression after STI.

\section{Methods}

We evaluated patients with brain metastases treated with salvage surgery for local progression from October 2002 to July 2019 . These patients had undergone salvage surgery based on magnetic resonance imaging findings and/or clinical evidence of post-STI local progression and stable systemic disease. We employed two prospective strategies according to the eloquency of the lesions. Lesions in non-eloquent areas had been resected completely with a safety margin, utilizing a fence-post method; while lesions in eloquent areas had been treated with minimal resection and postoperative STI. Kaplan-Meier curves were used for the assessment of overall survival. Prognostic factors for survival were analyzed.

\section{Results}

Fifty-four salvage surgeries had been performed on 48 patients. The median age of patients was 63.5 years (range 36-79). The median interval from STI to surgery was 12 months. The median overall survival was 20.2 months from salvage surgery and 37.5 months from initial STI. Primary cancers were lung 31 , breast 9 , and others 8 . Local recurrence developed in 13 of 54 lesions (24\%). Leptomeningeal dissemination occurred after surgery in 3 patients (5.6\%). Primary breast cancer (breast vs. lung: HR: 0.17), (breast vs. others: HR: 0.08) and RPA class 1-2 (RPA 1 vs. 3, HR:0.13), (RPA 2 vs 3 , HR:0.4) were identified as good prognostic factors for overall survival (OS) in multivariate analyses. The peripheral neutrophil-to-lymphocyte ratio (NLR) of $\leq 3.65$ predicted significantly longer OS (median 25.5 months) than an NLR >3.65 (median 8 months).

\section{Conclusion}

We insist that salvage surgery leads to rapid improvement of neurological function and clarity of histological diagnosis. Salvage surgery is recommended for large lesions especially with surrounding edema either in eloquent or non-eloquent areas.

\section{Background}

Stereotactic irradiation (STI) is a primary treatment option in the initial management of patients with brain metastases [1]. It is utilized alone, as adjuvant therapy after resection surgery, or in combination with whole brain irradiation (WBRT) [2-4]. One year after treatment STI has demonstrated local control rates of 70 to $90 \%$ when used alone for metastases smaller than $3 \mathrm{~cm}$, irrespective of primary cancer histology [2, 5-7]. Late tumor recurrence and radiation injury are relatively rare events following STI. With improved local and systemic management in recent years, patients with brain metastases now survive for longer periods. These post-STI patients are showing late clinical deterioration with locally progressive mass lesions.

This local progression can possibly be any of these three pathological conditions: local recurrence of metastasis, radiation necrosis, or a combination of both The clinical and imaging features of local recurrence and radiation necrosis show considerable overlap. Even modern multimodal examinations demonstrate insufficient specificity in this context.

Patients with local progression are managed by either WBRT, repeat STI or surgery $[1,8]$. Each treatment modality has limitations: WBRT may cause exhaustion and frequent decline in higher cortical function, and is avoided or deferred unless it is necessary to control multiple brain lesions; repeat STI to the local progression leads to increased toxicity to the brain by a high-dose re-irradiation, especially if there is radiation necrosis or combination of recurrence and necrosis [9]; surgical resection is not a much-published treatment modality for post-STI local progression.

Surgery is recommended for accessible lesions, especially if symptoms are progressive. Surgery immediately reduces the mass effects of these lesions and enables pathological confirmation. However, most reports on salvage surgery consist of small cohorts and heterogeneous groups. Lack of published reports on salvage surgery could be because these are cancer patients with limited life expectancy, who may assume that control would be insufficient, and treatment would lead to excessive morbidity.

Although many patients suffering from local progression are seen in the recent years, few reports provide data on the indications for surgery and surgical techniques.

Unlike brain metastases before treatment, local progression lesions after STI show unclear margins, leading to a technical difficulty in surgical resection. Additionally, these lesions have a complex intermingling of cancer cells with injured brain or necrotic tissue [10-12]. Therefore, neurosurgeons employ two different approaches to avoid recurrence or cancer cell dissemination: (1) resection with safety margins around the local progression, or (2) intended minimal resection along the borders with planned postoperative STI. Since 2003, we have employed a prospective strategy with a safety margin, utilizing a fence-post method for local progressions in non-eloquent areas, and a minimal resection accompanied by postoperative STI for progressions in eloquent areas.

The aim of this study was to retrospectively evaluate our surgical resection techniques to treat locally progressive lesions, for feasibility, efficacy in quality of life (QOL), and indications. Particularly, we examined whether the peripheral blood neutrophil-to-lymphocyte ratio (NLR) before surgery was a prognostic marker for salvage surgery, as NLR is a useful prognostic marker in upfront surgery for brain metastases [13]. 


\section{Methods}

Analysis of the medical records was performed after approval by the Institutional Research Ethics Board of the Shizuoka Cancer Center (30-J53-30-1-3). Our ethics board waived the requirement for written informed consent for this retrospective observational study. After anonymizing the data, we reviewed the neurosurgical reports, survival data, corresponding plans of STI, images, and independent pathological reports by the two treating neurosurgeons (K.M. and Y.N.).

\section{Patients}

From June 2004 to July 2019, brain metastases in 827 patients were treated with stereotactic radiosurgery (SRS) or stereotactic radiotherapy (SRT) at our institute. We identified 48 patients with 54 lesions that required salvage surgery for local progression of brain metastases after stereotactic irradiation (STI: SRS or SRT) between October 2002 and July 2019. We included patients who underwent salvage surgery for local progression at our institute, even though STI had been performed at another institute. Five patients had undergone SRS twice for the same brain metastases. Thirty-six patients had received treatments for brain metastases before STI: WBRT alone $(n=17)$, chemotherapy alone $(n=9)$, and WBRT+ Chemotherapy $(n=10)$.

We evaluated the radiological and clinical data at follow-up clinic visits. Patients' general condition was assessed on the day of surgery and one month after surgery, using the Karnofsky Performance Score (KPS). MR imaging was performed every 3 months after STI unless the treating oncologist/neurosurgeon had requested more frequent imaging.

Routine radiological data of patients with brain metastases included unenhanced T2- FLAIR, T1 and diffusion-weighted images, ADC-maps, and contrastenhanced T1-images. Local progression was suspected at the site of STI if MR imaging showed regrowth of an enhanced mass months after any decrease in size. In selected cases with suspected local progression, we added perfusion-weighted CT scans with CBV-maps using a 320-raw CT scanner (Aquilion ONE, Canon Medical Systems) [14]. We did not conduct positron emission tomography scans.

\section{STI as initial treatment for brain metastases}

STI alone was used to treat 46 lesions, and STI + WBRT was used to treat 8 lesions. Radiation oncologists performed STI using the linear accelerator stereotactic radiosurgery system (m3, Brain LAB, or TrueBeam STx, Varian). Dose selection was made on the basis of tumor volume, multiplicity, location or eloquency, previous fractionated radiotherapy, and the prescription isodose guidelines of RTOG 90-05.

\section{Indications for salvage surgery}

Local progression, diagnosed on the basis of perfusion-weighted CT scans, contrast-enhanced MR images, and clinical status, guided the treatment decisions made by our multidisciplinary cancer board. Patients were considered eligible for salvage surgery if (1) they were in good systemic condition with controlled or stable disease (2) the lesion was surgically accessible, (3) rapid progression mandated an early decompression, and (4) no other treatment options remained except surgery. Patients with an unknown primary cancer were also considered eligible for resection surgery.

\section{Surgical techniques}

During surgery, macroscopic borders between the brain and the local progression are unclear because the irradiated tumor, necrotic tissue, and the gliotic brain have similar gross appearances [11]. To preserve the maximum brain function, surgical dissection borders were planned in two ways. In the eloquent areas of the brain, we dissected the mass lesion in its border, allowing for minimum resection. and gave postoperative SRT or WBRT if necessary. In the non-eloquent areas, we used the navigation-guided fence post method to remove lesions totally, along with abnormal surrounding tissue and surrounding safety margins, without any adjuvant irradiation [15]. Fig. 1 shows a representative case of local progression during navigation surgery (Fig. $1 \mathrm{~A}$ ). An enhanced mass is seen in the occipito-parietal region with navigation trajectory (Fig. $1 \mathrm{~B}$ ), and the histopathological picture of the border zone is shown (Fig. $1 \mathrm{C}$ ).

\section{Statistical analysis}

Overall survival (OS) was calculated from the date of salvage surgery for local progression to the date of death due to any cause. Statistical analysis was performed using JMP (version 11, SAS Institute), and data for OS were analyzed using the Kaplan-Meier method. OS values were compared using the log-rank test. Frequency analysis was performed using Fisher's exact test. P-value $\leq 0.05$ was considered statistically significant.

\section{Results}

\section{Patient and tumor characteristics}

A total of 54 salvage surgeries were performed for local progression in 48 patients, including twice for the same lesion in two patients, and for two different lesions in three patients (Table 1). If this 18-years observation period is divided into halves, salvage surgeries increased in number from 20 cases in the first 8 years (mean 2.5 cases/year) to 34 cases in the recent 8 years (mean 4.25 cases/year). The series included 32 men and 16 women as a total number of patients with a median age of 63.5 years (range 36-79 years) at the time of salvage surgery. Primary cancers were lung in 31 (64.6\%), breast in 9 (18.8\%) and others in 8 (16.6\%) patients (renal cell carcinoma 2, melanoma 2, colon cancer 2, uterus 1, and mediastinum carcinoma 1). The median diameter of the enhanced lesions was $35 \mathrm{~mm}$ (range 19-58 mm).

Twenty patients had received systemic therapy after STI, and before local progression was detected ( $\mathrm{n}=8$ for cytotoxic chemotherapy, $\mathrm{n}=9$ for targeted therapy, $n=3$ for immuno-checkpoint inhibitor therapy). For 29 of 54 (53.7\%) lesions, local progression in the brain was the only metastatic complication. In 29 
of the 54 lesions (53.7\%), there was no systemic metastasis at the time of salvage brain surgery, local brain progression being the only metastatic complication. . After salvage surgery, 18 patients required systemic therapy ( $n=6$ for cytotoxic chemotherapy, $n=9$ for targeted therapy, and $n=3$ for immunocheckpoint inhibitor therapy).

Twenty-six lesions (48\%) were removed with minimum resection technique as they were in the eloquent areas, and 28 lesions (52\%) were removed with surrounding free margin for safety (Table 1). Twelve of the 26 lesions treated with minimal resection (46.1\%) were treated with either postoperative adjuvant radiosurgery or WBRT. The median interval from initial STI to the salvage surgery was 12 months (range 0.5-125.3 months).

\section{Survival and Quality of Life}

Median OS after salvage surgery was 20.2 months (Fig. 2 A). In the alive patients, the probability of local failure after salvage surgery did not reach a median after following up for 11.2 (median) months (range 0.9-129.2 months). Median OS after upfront STI was 37.5 months in all the patients ( $\mathrm{n}=48$ ), 37.5 months in patients with either pure or combination histological recurrence $(n=42)$ and 40.3 months in patients with pure histological necrosis $(n=6)(P=0.396)$.

We conducted univariate and multivariate analyses for survival despite the small $\mathrm{n}$ value for patients and events (Table 2). Tumor location, primary cancer histology and RPA classes correlated significantly with survival (Fig. 2). Multivariate analyses demonstrated that breast cancer, and RPA classes 1 or 2 versus class 3 correlated significantly with longer survival (Table 2). We did not exclude patients of RPA class 3 and low KPS from being candidates for resection surgery, as they comprised a large percentage (53\% RPA class 3 and $57 \%$ low KPS) of our cohort (Table 1). Local recurrence and leptomeningeal dissemination did not correlate with the selection of surgical technique. The local recurrence rate was $24 \%$ (13/54 cases) one year after resection surgery, and leptomeningeal dissemination was $5.6 \%$ at the end of the observation period (Table 3 ).

Fig. 3 demonstrates changes in KPS of individual patients. Preoperatively, 31 of 54 cases (57.4\%) presented KPS $30-60 \%$, and 23 of 54 cases (42.6\%) presented KPS $70-100 \%$. Twenty-three of 31 cases (74.2\%) with worse KPS (30-60\%) showed improvement of KPS postoperatively. Among 36 of 54 (66.7\%) cases with neurological deficits before surgery, 27 (75\%) cases showed improvements, seven (19.4\%) showed no change, and two (5.6\%) deteriorated.

Preoperative NLR was evaluable in 53 cases. The optimum NLR threshold value was identified as 3.65 for survival time on an ROC curve (Fig. 4 A). The patients with an NLR $\leq 3.65$ showed significantly longer median $O S$ than those with an $N L R>3.65,25.5$ months $(N=31)$ versus 8 months $(N=22)$ respectively (Fig. 4 B, p=0.024).

\section{Adverse effects of salvage surgery}

No mortality occurred within 30 days of salvage surgery in our cohort. Two patients (3.7\%) showed deterioration in their KPS, due to the progression of primary cancer after brain surgery, not due to neurological morbidity (Fig. 3).

\section{Discussion}

STI is the primary treatment for newly diagnosed brain metastases, especially if they are small and inaccessible. Local progression of brain metastases after upfront treatment with STI is seen more often now because of better survival of these patients, and the demand for salvage treatment is now more than ever [16]. In our study, salvage surgery was done for 20 patients in the first 8 years, and for 34 patients in the recent 8 years.

Median OS after upfront STI was 37.5 months for all 48 patients, 37.5 months for recurrences with pure or combined histology ( $\mathrm{n}=42$ ), and 40.3 months for patients with pure radiation necrosis $(n=6)(p=0.13)$. Median OS noted in previously published studies was much lower at 7.5 to 19 months (Table 4$)[10,11$, 17-20]. The longer median survival in our study can be attributed to the development of systemic therapy, improved care of cancer patients, and advances in surgical techniques.

Overall survival of patients with brain metastases also depends on the outcome of systemic primary cancers. However, these patients' functional outcome depends essentially on the CNS lesions. The goal of CNS treatment is to delay neurological progression long enough to facilitate the treatment of primary systemic metastases. Therefore, we should consider functional outcomes along with OS while considering treatment options for individual patients with brain local progression. [21]

Treatment decisions for brain local progression should be based on the functional status, lesion volume and surrounding edema, previous treatments, and the type of primary cancer [21]. Surgical removal, repeated in-field radiosurgery, WBRT, systemic therapy, or a combination of these can be chosen, depending on these factors.

Surgery remains an effective salvage treatment option with two important benefits: immediate reduction of the mass effects and histological confirmation. Salvage surgery led to overall local control rates of 69 to $100 \%$, and a median OS of 7.5 to 20.2 months, even for large lesions (Table 4).

Genetic and molecular information of cancer cells has become a recent clinical focus, because of reports showing drafting and variation of genetic markers in metastatic cancer cells $[22,23]$. Pathological analysis of surgical specimens may present new opportunities for targeted therapy.

In our study, histological examination revealed that $13 \%$ of the local progression lesions were radiation necrosis alone, and $87 \%$ were a heterogeneous combination of necrosis and cancer cells. Previous studies have shown pure radiation necrosis in 0-50\% of lesions obtained by salvage surgery (Table 4 ). The preoperative differential is not always easy, because both radiation necrosis and tumor recurrence present similar clinical and radiological findings, and a majority of these lesions comprise a combination of necrosis and cancer cells [20,24]. Without histological confirmation, repeated irradiation can lead to deterioration of necrosis and brain edema. 
Retrospective studies on the one-year outcome of repeated radiosurgery for local progression reported that local control was 61 to $88 \%$, and 0 S was 37 to $90.6 \%$ [25-27]. Toxicity was reported as overall necrosis rates 9.2 to $19 \%$ after the repeated SRS or SRT [25, 26]. Necrosis after repeated STI was shown to be significantly associated with the irradiated volume and the cumulative dose [16]. For large lesions with surrounding edema, repeat SRS may lead to a risk of local progression as the majority of these lesions consist of a combination of radiation necrosis and cancer cells, surrounded by the injured brain. In our study, repeated in-field STI was used for cancer cells remaining after minimal resection, in eloquent areas only. The risk of radiation necrosis due to repeated STI is reduced after decompressive surgery, because of less target volume and less involved normal tissue volume in the intended field.

We treated patients even if their prognostic scores were poor. $50 \%$ of patients in our cohort were RPA class 3 , whereas these advanced class patients were maximum of $30 \%$ in previous studies (Table 4). RPA classes were significantly correlated with the median OS (Table 2). Interestingly, the median OS of the whole cohort in our study was longer than the median OS in previous studies. We offered surgical resection to patients with lower KPS when we expected that neurological improvement would lead to a better general condition. Very little has been reported about postoperative functions after salvage surgery. In our study, 23 of 54 cases showed improvement in KPS after salvage surgery(Fig. 3). Sixteen patients returned to their systemic therapy for primary cancer soon after recovering from salvage surgery.

Although the numbers of patients presenting with local progression are increasing in recent years, most studies on salvage surgery, published before 2014, comprised of small cohorts (Table 4). This lack of recent data may be due to patients assuming upon a high risk of surgical resection and general anesthesia in heavily treated patients with brain metastases.

Surgical resection is safe for local progression after STI in selected patients. Surgical mortality rates range from zero in Telera's series [20] and ours, to $3 \%$ in the series of Vecil [17] and Truong [10] (Table 4). Although these surgical mortality data are of patients with heavily treated cancer, the rates were not worse than the data of general patients who underwent craniotomy for brain tumors. If we compare surgical morbidity data, previous studies reported little regarding postoperative neurological function, KPS or QOL. In our study, for lesions in eloquent areas, the minimum resection technique was used to preserve surrounding normal tissue, to achieve the best possible neurological function and KPS. Postoperative STI was used only if active cancer cells had invaded the surrounding brain and leptomeningeal layers. This combination strategy was as effective as resection with free margin and no postoperative radiation, in achieving local control and preventing dissemination (Table 3). This result emphasizes that proper selection of surgical technique contributes to a better functional outcome as well as curability. Although resection with free margin is an effective surgical technique for metastatic lesions with tissue invaded by cancer cells, it can be employed only in non-eloquent areas.

Two of our patients showed a deterioration of KPS, which occurred due to unexpected and rapid progression of primary cancer after salvage surgery, and clearly not due to neurological progression. Preoperative thorough assessments are complex challenges, especially in patients with heavily treated cancer. In this study, NLR has proven itself once again as a reliable marker to evaluate the general condition of patients with local progression. Previously, this was indicated in our study on upfront surgery for brain metastases [13]. NLR is a simple peripheral blood sample method and would help in the decision-making for resection surgery. We have various assessment tools to predict the survival prognosis of patients with brain metastases [28, 29]. However, we do not yet have any assessment tools to predict the functional outcome of brain metastases patients after local or systemic treatments. Long-term observation of large cohorts is necessary to predict the functional outcome of brain metastases patients.

Our study has some limitations, as it was a retrospective study of therapeutic outcomes with surgical resection only. We had a concrete plan to select patients for resection, and observe in the postoperative period with MR imaging. Planning for a control group was not ethical for this relatively rare, progressive and devastating condition. The patient cohort was small because this is a study in a single cancer center. A majority of the patients had primary cancers of lung and breast, but only a few had melanoma as a primary. This is an ethnical tendency that might taint a direct comparison of our outcomes with previous studies on Western populations.

\section{Conclusion}

Our retrospective study shows that salvage surgery after upfront STI is safe and gives good functional outcome in patients with local progression of brain metastases. Histologically, a majority of these lesions were a combination of necrosis and cancer cells. Additionally, peripheral blood NLR proved to be a reliable marker to assess the general condition of patients who were heavily treated, and presented with local progression.

We insist that surgical resection leads to rapid improvement of neurological function, and aids histological diagnosis. Salvage surgery is recommended for large lesions, especially if there is surrounding edema, in both eloquent and non-eloquent areas. Minimal resection technique combined with postoperative STI is recommended for lesions in the eloquent areas and removal with safety margin around the local progression for lesions in non-eloquent areas.

\section{Abbreviations}

STI, stereotactic irradiation; WBRT, whole brain radiation therapy; QOL, quality of life; NLR, neutrophil-to-lymphocyte ratio; SRS, stereotactic radiosurgery; SRT, stereotactic radiotherapy; KPS, Karnofsky performance score; FLAIR, fluid -attenuated inversion recovery; ADC, apparent diffusion coefficient; CBV, cerebral blood volume; RTOG, radiation therapy oncology group; RPA class, recursive partitioning analysis; CNS, central nervous system, OS, overall survival

\section{Declarations}

\section{Acknowledgements}

Not applicable. 
Funding

This work has not been funded.

\section{Availability of data and materials}

The datasets analyzed during the current study are available from the corresponding author on reasonable request.

\section{Authors' contributions}

KM designed the study with YN. KM, NH, and SD collected data. $\mathrm{KM}, \mathrm{NH}$, and SD participated in statistical analysis. $\mathrm{KY}, \mathrm{HO}$, Ton, $\mathrm{HA}$, and $\mathrm{HH}$ performed radiation therapy. Toi and TS was involved in all pathologic analysis including preparation of histopathology figures. KM and YN interpreted results, and prepared and drafted the manuscript. All authors read and approved the final manuscript.

\section{Competing interest}

The authors declare that they have no competing interests.

\section{Consent for publication}

Not applicable.

\section{Ethics approval and consent to participate}

Approval for this study was obtained from ethical review board of Shizuoka Cancer Center. Individual written informed consent was waived because this study was retrospective in design and based on database extracted records. The waivers of participant consent were approved by the ethical review boards of Shizuoka Cancer Center.

\section{References}

1. Soffietti R, Abacioglu U, Baumert B, Combs SE, Kinhult S, Kros JM, et al. Diagnosis and treatment of brain metastases from solid tumors: guidelines from the European Association of Neuro-Oncology (EANO). Neuro Oncol. 2017;19:162-74.

2. Aoyama H, ShiratoH, Tago M, Nakagawa K, Toyoda T, Hatano K, et al. Stereotactic radiosurgery plus whole-brain radiation therapy vs stereotactic radiosurgery alone for treatment of brain metastases: a randomized controlled trial. 2006;295:2483-91.

3. Yamamoto M, Serizawa T, Shuto T, Akabane A, Higuchi Y, Kawagishi J, et al. Stereotactic radiosurgery for patients with multiple brain metastases (JLGK0901): a multi-institutional prospective observational study. Lancet Oncol. 2014;15:387-95.

4. KayamaT, Sato S, Sakurada K, Mizusawa J, Nishikawa R, Narita Y, et al. Effects of surgery with salvage stereotactic radiosurgery versus surgery with whole-brain radiation therapy in patients with one to four brain metastases (JCOG0504): A Phase III, noninferiority, randomized controlled trial. J Clin Oncol. 2018;36:3282-9.

5. FlickingerJC, Loeffler JS, Larson DA. Stereotactic radiosurgery for intracranial malignancies. Oncology (Williston Park) 1994;8:81-6.

6. Bhatnagar A, Heron DE, Kondziolka D, Lunsford LD, Flickinger JC. Analysis of repeat stereotactic radiosurgery for progressive primary and metastatic CNS tumors. Int J Radiat Oncol Biol Phys. 2002;53:527-32.

7. Petrovich Z, Yu C, Giannotta SL, O'Day S, Apuzzo ML. Survival and pattern of failure in brainmetastasis treated with stereotactic gamma knife radiosurgery. J Neurosurg. 2002;97(5 Suppl):499-506.

8. FranchinoF, Rudà R, Soffietti R. Mechanisms and Therapy for Cancer Metastasis to the Brain. Front Oncol. 2018;8:161.

9. Rae A,Gorovets D, Rava P, Ebner D, Cielo D, Kinsella TJ, et al. Management approach for recurrent brain metastases following upfront radiosurgery may affect risk of subsequent radiation necrosis. Adv Radiat Oncol. 2016;1:294-9.

10. Truong MT, St Clair EG, Donahue BR, Rush SC, Miller DC, Formenti SC, et al. Results of surgical resection for progression of brain metastases previously treated by gamma knife radiosurgery. 2006; 59:86-97.

11. Jagannathan J, Bourne TD, Schlesinger D, Yen CP, Shaffrey ME, Laws ER Jr, et al. Clinical and pathological characteristics of brain metastasis resected after failed radiosurgery. Neurosurgery. 2010;66:208-17.

12. Nath SK, Sheridan AD, Rauch PJ, Yu JB, Minja FJ, Vortmeyer AO, et al. Significance of histology in determining management of lesions regrowing after radiosurgery. J Neurooncol. 2014;117:303-10

13. Mitsuya K, Nakasu Y, Kurakane T, Hayashi N, Harada H, Nozaki K. Elevated preoperative neutrophil-to-lymphocyte ratio as a predictor of worse survival after resection in patients with brain metastasis. J Neurosurg. 2017;127:433-7.

14. Jain R, Scarpace L, Ellika S, Schultz LR, Rock JP, Rosenblum ML, et al. First-passperfusion computed tomography: initial experience in differentiating recurrent brain tumors from radiation effects and radiation necrosis. 2007;61:778-86.

15. Nakasu Y, Mitsuya K, Hayashi N, Ito I. [Two Surgical Techniques for Metastatic Brain Tumors: Minimum Resection and Removal with Safety Margin]. No Shinkei Geka. 2016;44:221-6. (Jpn)

16. Balermpas P, Stera S, Müller von der Grün J, Loutfi-Krauss B, Forster MT, Wagner M, et al. Repeated in-field radiosurgery for locally recurrent brain metastases: Feasibility, results and survival in a heavily treated patient cohort. PLoS One. 2018;13:10.1371/journal.pone.0198692. 
17. Vecil GG, Suki D, Maldaun MV, Lang FF, Sawaya R. Resectionof brain metastases previously treated with stereotactic radiosurgery. J Neurosurg. 2005;102:209-15.

18. Kano H, Kondziolka D, Zorro O, Lobato-Polo J, Flickinger JC, Lunsford LD. The results of resectionafter stereotactic radiosurgery for brain metastases. J Neurosurg. 2009;111:825-31.

19. Schackert G,Schmiedel K, Lindner C, Leimert M, Kirsch M. Surgery of recurrent brain metastases: retrospective analysis of 67 patients. Acta Neurochir (Wien). 2013;155:1823-32.

20. TeleraS, Fabi A, Pace A, Vidiri A, Anelli V, Carapella CM, et al. Radionecrosis induced by stereotactic radiosurgery of brain metastases: results of surgery and outcome of disease. J Neurooncol. 2013;113:313-25.

21. AmmiratiM, Cobbs CS, Linskey ME, Paleologos NA, Ryken TC, Burri SH, et al. The role of retreatment in the management of recurrent/progressive brain metastases: a systematic review and evidence-based clinical practice guideline. J Neurooncol. 2010;6:85-96.

22. HanB, Tjulandin S, Hagiwara K, Normanno N, Wulandari L, Laktionov K, et al. EGFR mutation prevalence in Asia-Pacific and Russian patients with advanced NSCLC of adenocarcinoma and non-adenocarcinoma histology: The IGNITE study. Lung Cancer 2017;113:37-44.

23. FischerGM, Jalali A, Kircher DA, Lee WC, McQuade JL, Haydu LE, et al. Molecular Profiling Reveals Unique Immune and Metabolic Features of Melanoma Brain Metastases. Cancer Discov. 2019;9:628-45.

24. HoefnagelsFW, Lagerwaard FJ, Sanchez E, Haasbeek CJ, Knol DL, Slotman BJ, Vandertop WP. Radiological progression of cerebral metastases after radiosurgery: assessment of perfusion MRI for differentiating between necrosis and recurrence. J Neurol. 2009;256:878-87.

25. Minniti G, Scaringi C, Paolini S, Clarke E, Cicone F, Esposito V, et al. Repeated stereotactic radiosurgery for patients with progressive brain metastases. J Neurooncol. 2016;126:91-7.

26. Koffer P, Chan J, RavaP, Gorovets D, Ebner D, Savir G, et al. Repeat Stereotactic Radiosurgery for Locally Recurrent Brain Metastases. World Neurosurg. 2017;104:589-93.

27. Rana N, Pendyala P, Cleary RK, Luo G, Zhao Z, Chambless LB, et al. Long-term Outcomes after Salvage Stereotactic Radiosurgery (SRS) following In-Field Failure of Initial SRS for Brain Metastases. Front Oncol. 2017;7:279. org/10.3389/fonc.2017.00279.

28. Gaspar LE, Scott C, Murray K, Curran W. Validation of the RTOG recursive partitioning analysis (RPA) classification for brain metastases. Int J Radiat Oncol Biol Phys. 2000;47:1001-6.

29. SperdutoPW, Chao ST, Sneed PK, Luo X, Suh J, Roberge D, et al. Diagnosis-specific prognostic factors, indexes, and treatment outcomes for patients with newly diagnosed brain metastases: a multi-institutional analysis of 4,259 patients. Int J Radiat Oncol Biol Phys. 2010;77:655-61.

\section{Tables}


Table 1 Patient characteristics

\begin{tabular}{|c|c|}
\hline & No. (\%) \\
\hline Patients & 48 \\
\hline Lesions & 54 \\
\hline Median overall survival from surgery (months) & 20.2 \\
\hline Median age at surgery (years) & 63.5 \\
\hline Median time from STI to surgery (months) & 12 \\
\hline \multicolumn{2}{|l|}{ Gender } \\
\hline Male & $32(66.7)$ \\
\hline Female & $16(33.3)$ \\
\hline \multicolumn{2}{|l|}{ Primary cancer } \\
\hline Lung & $31(64.6)$ \\
\hline Breast & $9(18.8 \square$ \\
\hline Others & $8(16.6)$ \\
\hline \multicolumn{2}{|l|}{ Location } \\
\hline Supratentrial & $47(87)$ \\
\hline Infratentrial & $7(13)$ \\
\hline \multicolumn{2}{|l|}{ Neurological deficit } \\
\hline Yes & $36(67)$ \\
\hline No & $18(33)$ \\
\hline \multicolumn{2}{|l|}{ RPA classification at surgery } \\
\hline Class1 & $7(13)$ \\
\hline Class2 & $18(33)$ \\
\hline Class3 & $29(53)$ \\
\hline \multicolumn{2}{|l|}{ Radiotherapy before salvage surgery } \\
\hline STI & $46(85)$ \\
\hline SRS & $24(44.5)$ \\
\hline SRT & $17(31.5)$ \\
\hline Repeated STI & $5(9)$ \\
\hline WBRT+STI & $8(15)$ \\
\hline \multicolumn{2}{|l|}{ Surgical method } \\
\hline Minimum resection & $26(48)$ \\
\hline with radiotherapy & $12(22)$ \\
\hline without radiotherapy & $14(26)$ \\
\hline Resection with free margine & $28(52)$ \\
\hline \multicolumn{2}{|l|}{ Pathological diagnosis } \\
\hline Tumor recurrence + Necrosis & 47 (87) \\
\hline Radiation necrosis alone & $7(13)$ \\
\hline \multicolumn{2}{|l|}{ Extent of resection } \\
\hline Gross total removal & $48(89)$ \\
\hline Subtotal removal & $6(11)$ \\
\hline \multicolumn{2}{|l|}{ KPS before surgery } \\
\hline $90-100$ & $18(33)$ \\
\hline $70-80$ & $5(9)$ \\
\hline $50-60$ & $20(37)$ \\
\hline $30-40$ & $11(20)$ \\
\hline $0-20$ & $0(0)$ \\
\hline \multicolumn{2}{|l|}{ KPS after surgery } \\
\hline $90-100$ & $24(44)$ \\
\hline $70-80$ & $16(30)$ \\
\hline $50-60$ & $10(18.5)$ \\
\hline $30-40$ & $3(5.5)$ \\
\hline $0-20$ & $1(2)$ \\
\hline \multicolumn{2}{|l|}{ Radiotherapy after salvage surgery } \\
\hline Yes & $20(38)$ \\
\hline WBRT & $10(18.5)$ \\
\hline STI & $10(18.5)$ \\
\hline No & $34(62)$ \\
\hline \multicolumn{2}{|l|}{ Treatment period } \\
\hline $2002-2010$ & $19(40)$ \\
\hline 2011-2019 & $29(60)$ \\
\hline
\end{tabular}


Table 2 Univariate and multivariate analysis of patient and treatment factors for survival

Tested Variable

Age at surgery (median; 63.5)

Number (\%) median OS (M) P value

Tested Variable

HR $95 \% \mathrm{CI}$

$P$ value

$<63$-years

$\geq 63$-years

$21(43.8)$

$27(56.2)$

29.2

0.4

Median time from STI to surgery (12mo)

16.8

$\geq 12$ months

$<12$ months

$22(45.8)$

32.9

0.13

Pathological diagnosis

$26(54.2)$

13.1

Radiation necrosis alone

Tumor recurrence + Necrosis

$6(12.5) \quad 22.8 \quad 0.76$

Gender

Female

Male

42 (87.5)

20.2

Location

$\begin{array}{lll}16(33.3) & 29 & 0.11\end{array}$

Supratentrial

$32(66.7)$

16.8

Infratentrial

$42(87.5)$

6 (12.5)

25.5

9.1

0.016

Location

Supra- vs Infratentrial 0.5

0.5

$0.18-1.52$

0.2

\section{Primary cancer}

Breast

Lung

$9(18.8)$

Others

$31(64.6)$

43

8 (16.6)

16.8

9.4

Neurological deficit

No

Yes

$15(31.3)$

33 (68.7)

21.9

16.8

RPA

6 (12.5)

$18(37.5)$

NR

21.9

$24(50)$

11.2

Class 1

$23(48)$

25.5

$25(52)$

17.9

Resection with free margine

$6(12.5)$

28.2

$42(87.5)$

20.2

Gross total removal

$15(31.3)$

20.2

Radiotherapy after salvage surgery

Yes $33(68.7)$

16.8

\section{Primary cancer} Breast vs Others

पNR; not reached
Breast vs Lung Lung vs Others

0.56

0.003

Lung vs Others

\section{RPA}

0.023 Class 1 vs 3

0.7

0.98

0.38
Surgical technique

16.8 $\begin{array}{lll}0.2 & 0.036-0.55 & 0.002\end{array}$

$\begin{array}{lll}0.1 & 0.013-0.34 & 7 \mathrm{E}-04\end{array}$

$0.5 \quad 0.2-1.2 \quad 0.12$

Class 2 vs 3

Class 1 vs 2

\begin{tabular}{|c|c|c|}
\hline 0.1 & $\mathbf{0 . 0 2}-0.51$ & $\mathbf{0 . 0 0 2}$ \\
\hline $\mathbf{0 . 4}$ & $\mathbf{0 . 1 6}-0.95$ & $\mathbf{0 . 0 4 2}$ \\
\hline 0.3 & $0.05-0-1.35$ & 0.13 \\
\hline
\end{tabular}

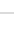


Table 3 Surgical technique and outcome

\begin{tabular}{ccccc}
\hline & $\begin{array}{c}\text { All } \\
\text { lesions }\end{array}$ & $\begin{array}{c}\text { Minimum resection +/- } \\
\text { SRT }\end{array}$ & $\begin{array}{c}\text { Resection with free } \\
\text { margin }\end{array}$ & P value \\
\hline $\begin{array}{c}\text { Number of } \\
\text { lesions }\end{array}$ & 54 & 26 & 28 & \\
\hline Local recurrence & $\begin{array}{c}13 / 54 \\
(24 \%)\end{array}$ & $9 / 26(34.6 \%)$ & $4 / 28(14.3 \%)$ & 0.07 \\
\hline $\begin{array}{c}\text { Leptomeningeal } \\
\text { Dissemination }\end{array}$ & $\begin{array}{c}3 / 54 \\
(5.6 \%)\end{array}$ & $3 / 26(11.5 \%)$ & $0 / 28(0 \%)$ & 0.105 \\
\hline
\end{tabular}

๑Fisher's exact test

Table 4 Reports of surgical resection for recurrent/ progressive brain metastases

after STI

First Author, Number Surgical RPA class Previous

Year [ref]

$$
\begin{gathered}
\text { of } \\
\text { patients }
\end{gathered}
$$

\begin{tabular}{|c|c|}
\hline Median & Rates of \\
\hline tumor & radiation \\
\hline volume & necrosis \\
\hline $\begin{array}{c}\text { or } \\
\text { maximum } \\
\text { diameter }\end{array}$ & $\begin{array}{c}\text { alone } \\
(\%)\end{array}$ \\
\hline
\end{tabular}
Median \# Pts with \# Pts with Surgical survival local dissemination mortality recurrence after surgery (\%)

\begin{tabular}{|c|c|c|c|c|c|c|c|c|c|c|}
\hline $\begin{array}{l}\text { Vecil, } 2005 \\
{[17]}\end{array}$ & 61 & 74 & $13 / 72 / 15$ & SRS & NR & $6 / 74(8)$ & 11.1 & $\begin{array}{l}13 / 74 \\
(17.6)\end{array}$ & NR & 3.0 \\
\hline $\begin{array}{l}\text { Truong, } \\
2006 \text { [10] }\end{array}$ & 32 & 32 & $13 / 87 / 0$ & SRS & $1.5 \mathrm{cc}$ & $\begin{array}{c}4 / 32 \\
(12.5)\end{array}$ & 8.9 & $9 / 32(28)$ & NR & 3.0 \\
\hline $\begin{array}{l}\text { Kano, } 2009 \\
{[18]}\end{array}$ & 58 & 58 & $38 / 52 / 10$ & SRS & $15.5 \mathrm{cc}$ & $0(0)$ & 7.6 & $\begin{array}{c}18 / 58 \\
(31)\end{array}$ & NR & 1.7 \\
\hline $\begin{array}{l}\text { Jagannathan, } \\
2010 \text { [11] }\end{array}$ & 15 & 15 & NR & SRS & $7.5 \mathrm{cc}$ & $\begin{array}{c}5 / 15 \\
(33.3)\end{array}$ & 11.3 & $0 / 15(0)$ & NR & NR \\
\hline $\begin{array}{l}\text { Schackert, } \\
2013 \text { [19] }\end{array}$ & 67 & 67 & $24 / 46 / 30$ & SRS & NR & NR & 7.5 & $\begin{array}{l}21 / 67 \\
(31.3)\end{array}$ & NR & NR \\
\hline $\begin{array}{l}\text { Telera, } 2013 \\
{[20]}\end{array}$ & 15 & 16 & $50 / 25 / 25$ & SRS & $\begin{array}{c}3 \mathrm{~cm} \\
(1.5-4.5)\end{array}$ & $\begin{array}{l}7 / 16 \\
(50)\end{array}$ & 19.0 & $0 / 16(0)$ & NR & 0.0 \\
\hline $\begin{array}{l}\text { Present } \\
\text { study, } 2019\end{array}$ & 48 & 54 & $13 / 31 / 56$ & $\begin{array}{l}\text { SRS or } \\
\text { SRT }\end{array}$ & $3.5 \mathrm{~cm}$ & $\begin{array}{l}7 / 54 \\
(13) \\
\end{array}$ & 20.2 & $\begin{array}{l}14 / 54 \\
(25.6) \\
\end{array}$ & $3 / 54(5.6)$ & 0.0 \\
\hline
\end{tabular} after
surgery
$(\%)$
(\%)

aNR; Not

reported, \# Pts: patients

\section{Figures}

Fig. 1
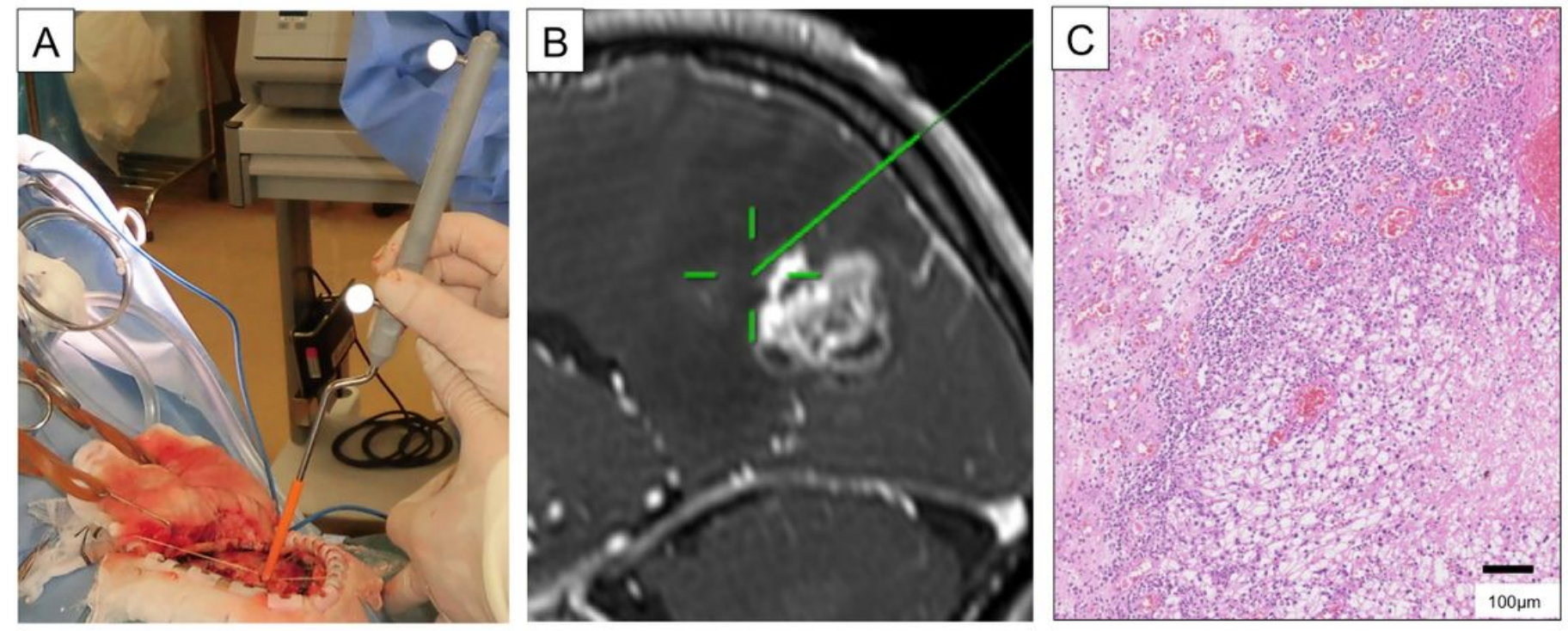
Figure 1

Local progression of brain metastasis from renal cell carcinoma previously treated with SRS was depicted at navigation surgery (a), with an enhanced mass with navigation trajectory in the occipito-parietal region (b). A histopathological picture of the border zone (c). The margin between the tumor and the brain was collapsed. Hematoxylin and eosin staining showed neutrophil infiltration at the tumor margin, gliotic changes and a large number of microvessels in the surrounding brain tissue (x10).
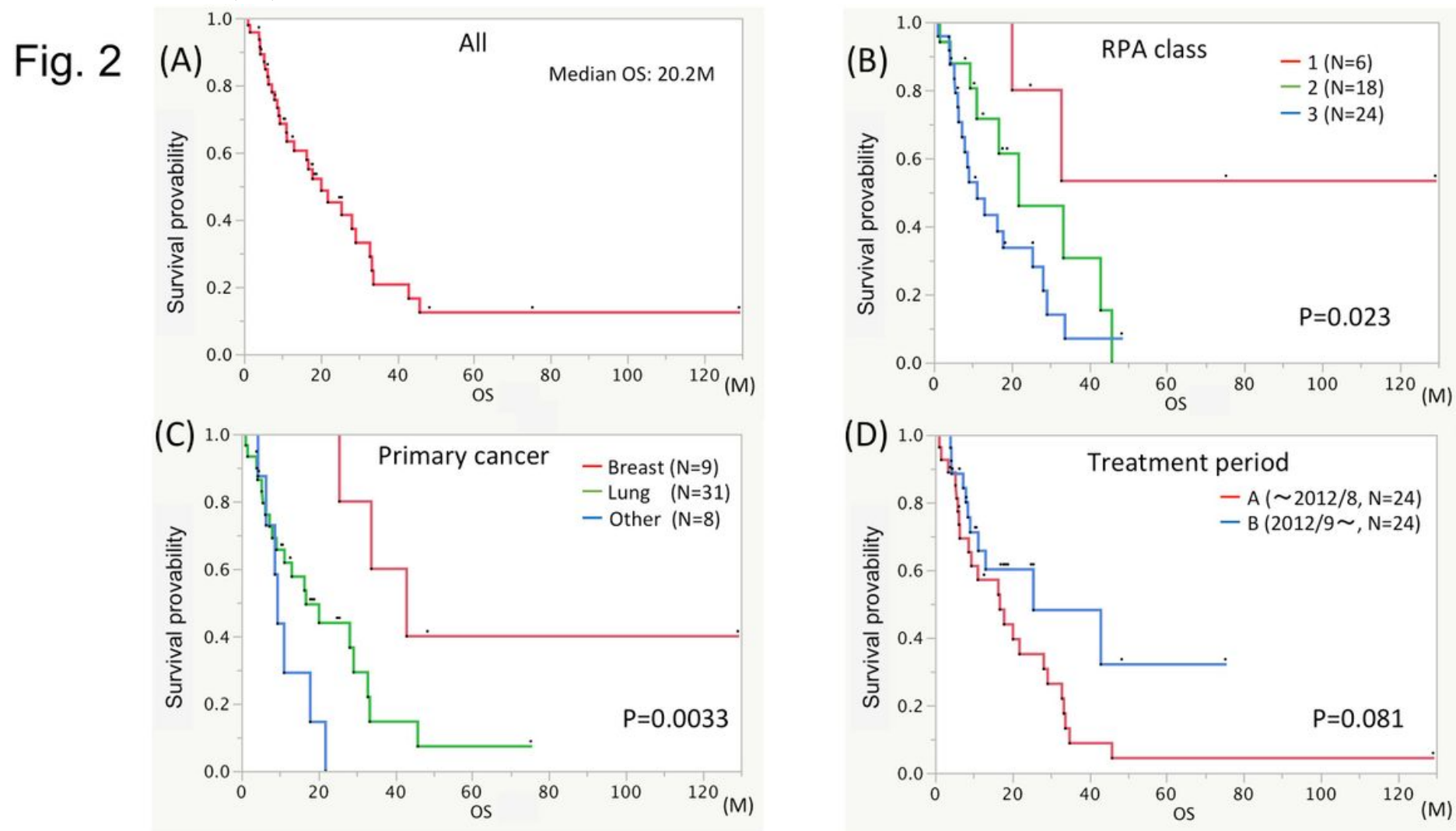

\section{Figure 2}

Median OS was 20.2 months from salvage surgery (a). RPA classes (b) and primary cancer histology (c) showed a significant correlation with OS on univariate analysis. Patients showed a trend towards longer survival in recent years (d). 
Fig. 3

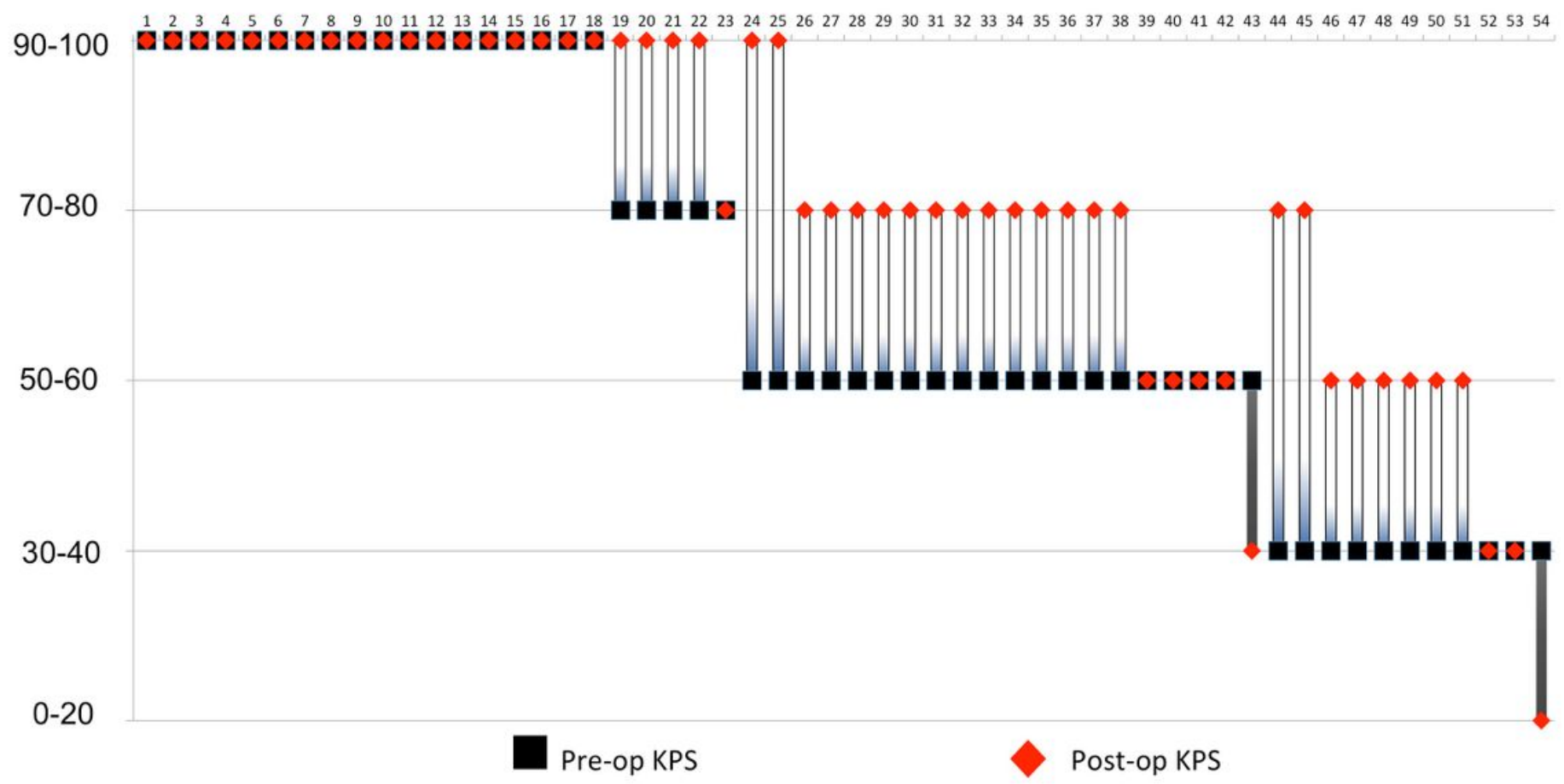

Figure 3

Changes of KPS in individual cases. Among 36 cases having lower KPS due to neurological deficits before surgery, 27 (75\%) cases showed improved KPS, seven (19.4\%) showed no change, and two (5.6\%) deteriorated.

Fig. 4

(A)

ROC curve

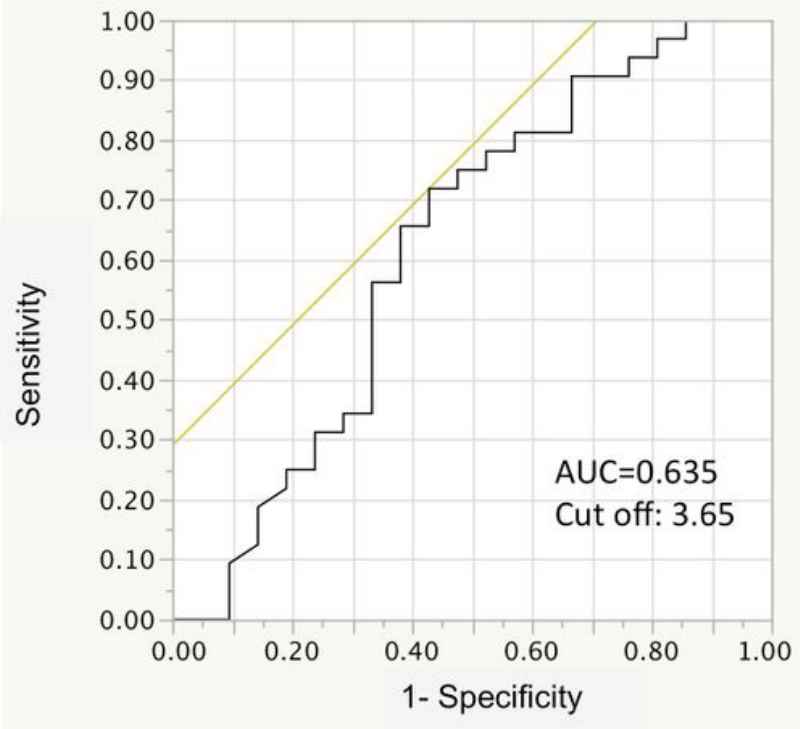

(B)

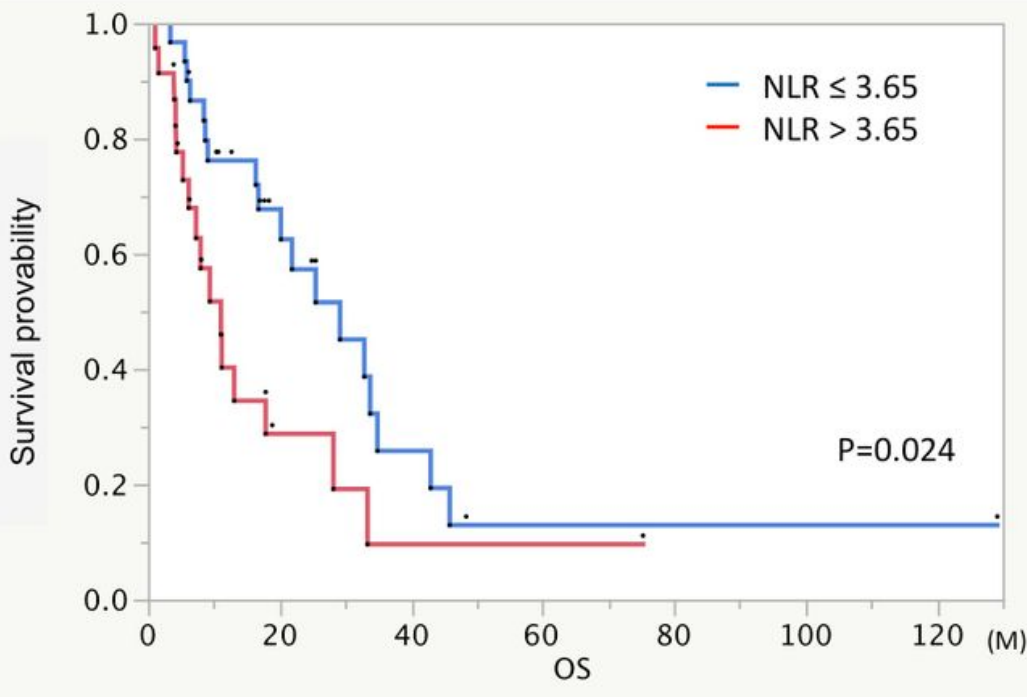

Figure 4 
NLR was evaluated by Receiver Operating Characteristic curves, showing a maximum area under the curve of 0.635 (a). Kaplan-Meier survival curves of patients with low preoperative NLR ( $\leq 3.65)$ were compared with those with a high NLR $(>3.65)$. The median OS was significantly longer in patients with a low NLR (25.5 months) than those with a high NLR (8 months) (b).

\section{Supplementary Files}

This is a list of supplementary files associated with this preprint. Click to download.

- Table3.xlsx

- Table4.xlsx

- Table1.xlsx

- Table2.xIsx 